\title{
https://doi.org/10.46813/2020-130-055 \\ ANOMALOUS TRANSPORT OF TRANSVERSELY ACCELERATED IONS IN LOWER HYBRID CAVITIES
}

\author{
N.A. Azarenkov ${ }^{1}$, A.D. Chibisov ${ }^{2}$, D.V. Chibisov ${ }^{1}$ \\ ${ }^{I}$ V.N. Karazin Kharkiv National University, Kharkiv, Ukraine; \\ ${ }^{2}$ H.S. Skovoroda Kharkiv National Pedagogical University, Kharkiv, Ukraine \\ E-mail: dmitriychibisov@karazin.ua
}

The transport of particles and heat for transversely accelerated ions in lower hybrid cavities due to drift turbulence is investigated. The transport equations for the conditions of lower hybrid cavities are obtained. It is shown that the anomalous transport of particles and heat across the geomagnetic field in the lower hybrid cavities is caused to the scattering of ions by random pulsations of drift turbulence. It was found that the diffusion and thermal diffusion of accelerated ions in the cavity occurs in a time comparable to the time of filling the cavity with the back ground plasma.

PACS: 52.35.Ra, 52.35.Mw

\section{INTRODUCTION}

One of the features of the lower hybrid cavities (LHC) in plasma of ionosphere, detected by spacecraft,is the presence of transversely accelerated ions (TAI), whose energies across the magnetic field range from 2 to $8 \mathrm{eV}$ reaching energies in these tails up to $30 \mathrm{eV}$ [1]. The fraction of TAI is about $10 \%$ of plasma ions in the cavity, while there is little or no effect upon the bulk ion temperature, which is few tenths of electron volts. Several mechanisms have been proposed to explain the presence of such ions in cavities, which are reduced to ion acceleration due to their interaction with the lower hybrid oscillations in the cavity. However in Ref. [1] notes that no complete, quantitative model of TAI production in LHC exists.

LHC are fairly stable formations. There are no direct measurements of the cavity lifetime. However, during the passage of spacecraft through the cavities (up to $0.1 \mathrm{~s}$ ), no changes in the characteristics of the cavities were observed. In particular, no changes in the plasma density, the level of lower-hybrid oscillations, or any evolution of TAI were detected during this time. This suggests that the lifetime of the cavities significantly exceeds $0.1 \mathrm{~s}$. Thus the lifetime of the cavity is large enough, but in the end, because there is no flow of energy from the outside, all the processes in it should weaken, and the cavity itself should disappear.

The possible mechanism leading to the disappearance of the LHC is the plasma diffusion across the earth's magnetic field towards the center of the cavity caused by the drift-wave turbulence of plasma in the LHC. It was shown in Refs. [2, 3], that the lower frequency drift-wave instability and the drift-wave plasma turbulence in the LHC is caused by the radial in homogeneity of the plasma density. Since the cavity has cylindrical symmetry, the analysis of the instability and the subsequent turbulent state of the plasma was carried out on the basis of the development and nonlinear interaction of small scale cylindrical waves in plasma [4-7]. The characteristic feature of the drift turbulence of plasma with cylindrical symmetry is the nonlinear instability of drift waves caused by the induced scattering ISSN 1562-6016. BAHT. 2020. №6(130)

PROBLEMS OF ATOMIC SCIENCE AND TECHNOLOGY. 2020, № 6. Series: Plasma Physics (26), p. 55-58. of small scale cylindrical waves by ions. In the model of drift turbulence for slab plasma, where the eigen waves are the plane sinusoidal waves, energy is transferred over the wave spectrum from the short-wavelength part to the long-wavelength part, where only the plasma size is a limitation. In the case of cylindrical plasma, the wavelength limitation is determined by the relation $k_{\perp} \rho_{s} \sim 1$, where $\rho_{s}=\rho_{T i} \sqrt{T_{e} / T_{i}}$. The longwavelength part of the oscillation spectrum is nonlinearly unstable.

As a result of anomalous diffusion due to drift turbulence, the depth of the cavity decreases while its size increases and eventually the cavity disappears [2, 3].

In this work, we study the evolution of the distribution function of the fraction of TAI. In contrast to bulk ions, which have a depletion of density at the center of the cavity, the TAI has a maximum at the center of the cavity, and the density decreases with increasing radius. We also assume that the energy of such ions decreases with radius, and investigate the diffusion and heat transport processes in this fraction of ions.

\section{DISTRIBUTIONS OF BULK AND TAI}

In homogeneous magnetized plasma, we consider the cylindrically symmetric depletion of density, whose axis coincides with $z$ - directed magnetic field and the dependence of the plasma density on the radius is in the form of an inverted Gaussian distribution [2]

$$
n(r)=n_{0}\left(1-a \exp \left(-\frac{r^{2}}{2 r_{0}^{2}}\right)\right)
$$

The velocity distribution for the components of plasma is assumed to be Maxwellian. The ion and electron temperature in the cavity does not depend on the radius. Then the distribution function for the plasma in LHC is [2]

$$
F_{\alpha}=\frac{n_{0}}{(2 \pi)^{3 / 2} \mathrm{v}_{T \alpha}^{3}}\left(1-a \exp \left(-\frac{R_{\alpha}^{2}}{2 R_{0 \alpha}^{2}}\right)\right) \exp \left(-\frac{\rho_{\alpha}^{2}}{2 \rho_{T \alpha}^{2}}-\frac{\mathrm{v}_{z}^{2}}{2 \mathrm{v}_{T \alpha}^{2}}\right),
$$

where the subscript $\alpha$ denotes the bulk ions (i) or electrons (e). We also assume that the cavity is filled with 
ions of much lower density, which have a transverse to the magnetic field energy much higher than the temperature of the bulk ions (TAI), and whose density has a Gaussian dependence on the radius. The distribution of the velocities of such ions is also Maxwellian with a much higher temperature, which can also depend on the radius. The distribution function for the TAI is [4]

$$
F_{T A l}=\frac{n_{0}}{(2 \pi)^{3 / 2} \mathrm{v}_{T} \rho_{T}^{2}} \exp \left(-\frac{R^{2}}{2 R_{0}^{2}}-\frac{\rho^{2}}{2 \rho_{T}^{2}}-\frac{\mathrm{v}_{z}^{2}}{2 \mathrm{v}_{T}^{2}}\right) \text {. }
$$

The joint distribution function of bulk ions and TAI is

$$
F=F_{i}+F_{T A I} \text {. }
$$

We now consider the evolution of the ion distribution function (4) due to low-frequency drift-wave turbulence, which is caused by the drift instability of the radially inhomogeneous plasma of the LHC. In Ref. [2], the excitation of low-frequency drift oscillations in the LHC was investigated taking into account only bulk ions, and the effect of TAI was neglected because of their low density. However, considering the inverse effect of drift turbulence on the distribution function, we believe that oscillations affect not only bulk ions, but also TAI.

\section{QUASI-LINEAR EQUATION FOR THE ION DISTRIBUTION FUNCTION}

To analyze the evolution of the ion distribution function due to drift turbulence, we use the quasi linear equation for cylindrically symmetric plasma obtained in Ref. [5], which as applied to low-frequency drift oscillations has the form

$$
\begin{aligned}
\frac{\partial F}{\partial t}=\frac{e^{2}}{m_{i}^{2}} & \sum_{m} \int d K I_{m}(K) \frac{m}{\omega_{c i}} \times \\
& \times \frac{\partial}{R_{i} \partial R_{i}} \frac{J_{m}^{2}\left(k_{\perp} R_{i}\right) v}{\omega_{m}^{2}(k)+v^{2}} \frac{m}{\omega_{c i}} \frac{\partial F}{R_{i} \partial R_{i}},
\end{aligned}
$$

where $F$ is determined by (4), $m_{i}$ is the mass of the ion, $m$ is the azimuthal wavenumber, $\omega_{c i}$ is the ion cyclotron frequency, $\omega_{m}(k)$ is a frequency of drift oscillations inside of LHC [2], $v$ is a frequency of collisions of ions with turbulent electrostatic fields of drift turbulence, in a state of saturation of drift turbulence $v=\gamma_{m}(k)$, where $\gamma_{m}(k)$ is the linear growth rate of drift instability [2], $I_{m}(K)$ is the spectral intensity of small-scale cylindrical waves, $J_{m}\left(k_{\perp} R_{i}\right)$ is the Bessel function. Thus, the evolution of the ion distribution function in the LHC occurs due to the scattering of ions by turbulent electrostatic fields of drift turbulence.

Rewrite the equation [5] as

$$
\frac{\partial F}{\partial t}=\frac{1}{R_{i}} \frac{\partial}{\partial R_{i}} R_{i} D_{i \perp} \frac{\partial F}{\partial R_{i}},
$$

where

$$
D_{i \perp}=\frac{c^{2}}{B_{0}^{2}} \sum_{m} \int d K I_{m}(K) \frac{m^{2}}{R_{i}^{2}} \frac{J_{m}^{2}\left(k_{\perp} R_{i}\right) v}{\omega_{m}^{2}(k)+v^{2}}
$$

is the diffusion coefficient. In the saturation state of drift turbulence the diffusion coefficient is [2]

$$
D_{i \perp}=\frac{c T_{e}}{e B_{0}} \frac{\rho_{s}}{R_{0}} .
$$

Now we use the equation [6] to study diffusion and thermal diffusion of TAI.

\section{DIFFUSION OF TAI}

Integrating eq. (5) over the velocities, we obtain the transport equation for the plasma ions in the cavity

$$
\frac{\partial n}{\partial t}=\frac{1}{r} \frac{\partial}{\partial r}\left(r D_{i \perp} \frac{\partial n}{\partial r}\right),
$$

where $n=n_{i}+n_{T A I}$ is the total density of bulk and TAI. This equation splits into two equations that are in no way related to each other. One of these equations describing the diffusion of volume ions is

$$
\frac{\partial n_{i}}{\partial t}=\frac{1}{r} \frac{\partial}{\partial r}\left(r D_{i \perp} \frac{\partial n_{i}}{\partial r}\right),
$$

where the initial distribution of the density along the radius is given by eq.(1). This equation was solved in $[2,3]$. The main result of this study was the dependence of plasma density in the cavity on the radius and on time:

$n(r, t)=n_{0}\left(1-\frac{a}{\left(1+\frac{2 D_{e, i \perp}}{r_{0}^{2}} t\right)} \exp \left[\frac{r^{2}}{2 r_{0}^{2}}\left(1+\frac{2 D_{e, i \perp}}{r_{0}^{2}} t\right)^{-1}\right]\right)$,

where $a$ is the initial depth of the cavity, and the depth of the cavity, depending on time, is

$$
a(t)=\frac{a}{\left(1+\frac{2 D_{e, i \perp}}{r_{0}^{2}} t\right)} .
$$

Thus, the cavity depth is inversely proportional to time. The time $t_{k}$, which corresponds to the change in the depth of the cavity by $k$ is

$$
t_{k}=\frac{(k-1)}{2 D_{i \perp}} r_{0}^{2} .
$$

It has also been estimated, that $t_{k}=0.25(k-1)$ and thus the cavity disappears in more or about $1 \mathrm{~s}$.

Now we consider the second equation obtained from (8), the diffusion equation for the TAI

$$
\frac{\partial n_{T A I}}{\partial t}=\frac{1}{r} \frac{\partial}{\partial r}\left(r D_{i \perp} \frac{\partial n_{T A I}}{\partial r}\right)
$$

In contrast to the dependence of the density on the radius for bulk ions (1), the TAI density has a Gaussian dependence on the radius

$$
n_{T A I}(r)=n_{0 T A I} \exp \left(-\frac{r^{2}}{2 r_{T A I}^{2}}\right) .
$$

Note, that the length of the in homogeneity of the radial distribution for TAI, $r_{T A I}$, may differ from the length of the in homogeneity of bulk ions $r_{0}$.

The solution to the equation similar to (12) with dependence $n(r)$ (1) is presented in Ref. [3]. Using the procedure for solving that equation, we obtain the dependence of TAI density in the cavity on the radius and on time as 


$$
n_{\text {TAI }}(r, t)=\frac{n_{0 T A I}}{\left(1+\frac{2 D_{i \perp}}{r_{T A I}^{2}} t\right)} \exp \left[-\frac{r^{2}}{2 r_{T A I}^{2}}\left(1+\frac{2 D_{i \perp}}{r_{T A I}^{2}} t\right)^{-1}\right] .
$$

The time evolution of the dependence of the TAI density in the cavity on the radius is shown in the Fig. 1, where the TAI densities versus radius are shown for different moments of time: $t_{0}=0 s, t_{1}=0.25 s, t_{2}=0.5 s, t_{3}=0.75 s, t_{4}=1 s ; \quad$ the parameters of cavity plasma are taken from the works $[2,3]$. Comparing the obtained dependence (15) with the dependence of the plasma density (10) we conclude that the diffusion processes of plasma and TAI occur simultaneously.

\section{HEAT TRANSPORT BY TAI}

To obtain the equation of heat transport in the cavity, we multiply the equation (6) by $m_{i} \mathrm{v}_{i \perp}^{2} / 2$ and integrate over the velocities. We get

$$
\frac{\partial w_{T A I}}{\partial t}=\frac{1}{r} \frac{\partial}{\partial r}\left(r D_{i \perp} \frac{\partial w_{T A I}}{\partial r}\right),
$$

where $w_{T A I}=w_{T A I}(r)=n_{T A I}(r) T_{T A I}(r)$, is the energy density of TAI, $T_{T A I}=m_{i} \mathrm{v}_{i T}^{2} / 2=m_{i} \rho_{T}^{2} / 2 \omega_{c i}^{2}$ is the average energy of motion of TAI across the magnetic field. Thus, the eq. (16) describes the transport of the ion energy density across the magnetic field. In order to obtain a solution to eq. (16), it is necessary to specify the initial distribution of the temperature of the TAI along the radius. Suppose that the temperature distribution of the TAI along the radius is Gaussian

$$
T_{T A I}(r)=T_{0 T A I} \exp \left(-\frac{r^{2}}{2 r_{T A I}^{2}}\right),
$$

that is, it corresponds to the dependence of the TAI density on the radius, (14). In general case, this distribution can have some other length of in homogeneity however, to simplify the calculations we have assumed this. Then the TAI energy density will be as follows

$$
w_{T A I}(r)=n_{0 T A I} T_{0 T A I} \exp \left(-\frac{r^{2}}{r_{T A I}^{2}}\right) .
$$

Using the procedure for solving the eq. (16) which presented in [3], we get

$$
w(r, t)=\frac{n_{0 T A I} T_{0 T A I}}{\left(1+\frac{4 D_{i \perp}}{r_{T A I}^{2}} t\right)} \exp \left[-\frac{r^{2}}{r_{T A I}^{2}}\left(1+\frac{4 D_{i \perp}}{r_{T A I}^{2}} t\right)^{-1}\right]
$$

In order to obtain the dependence of the temperature distribution of the TAI on time, considering that $w_{T A I}(r, t)=n_{T A I}(r, t) T_{T A I}(r, t)$, it is necessary to divide the energy density (19) by the particle density (15). We get

$T_{T A I}(r, t)=T_{0 T A I} \frac{\left(1+\frac{2 D_{i \perp}}{r_{T A I}^{2}} t\right)}{\left(1+\frac{4 D_{i \perp}}{r_{T A I}^{2}} t\right)} \times$

$$
\times \exp \left[-\frac{r^{2}}{2 r_{T A I}^{2}}\left(1+\frac{4 D_{i \perp}}{r_{T A I}^{2}} t\right)^{-1}\left(1+\frac{2 D_{i \perp}}{r_{T A I}^{2}} t\right)^{-1}\right]
$$

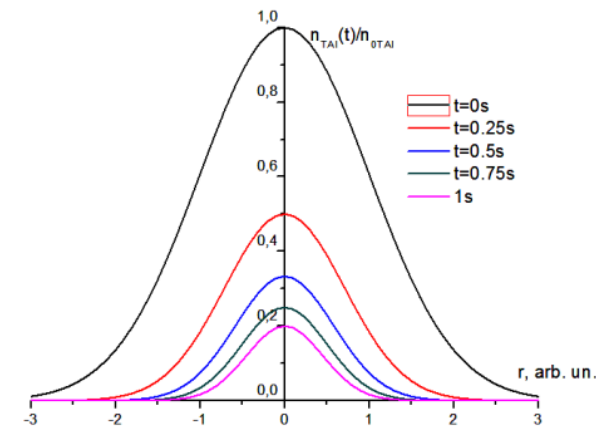

Fig. 1. The dependence of the TAI density in the cavity on the radius for different times

The time evolution of the dependence of the TAI density in the cavity on the radius is shown in the Figs. 1, 2

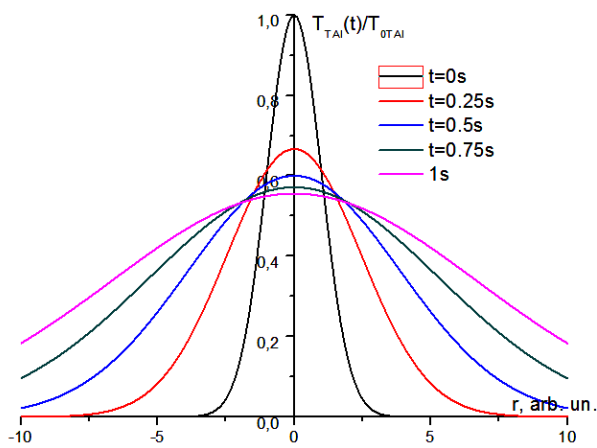

Fig. 2. The dependence of the TAI temperature in the cavity on the radius for different times

From (20) and Fig. 2 it follows that the cooling of the TAI in the center of the cavity occurs only to a certain level. At the same time, the ions are heated away from the cavity axis, which is caused by the diffusion of hot ions from the center of the cavity.

\section{CONCLUSIONS}

1. In the LHC, solitary structures of the Earth's ionosphere, due to the radial in homogeneity of the plasma density the turbulence of drift waves appears.

2. Drift turbulence leads to anomaly plasma diffusion across the geomagnetic field and filling the cavity.

3. One of the features of the LHC is the presence of (TAI), which interact with drift turbulence and diffuse across the magnetic field.

4. Drift turbulence also leads to thermal diffusion of TAI, as a result of which the ions in the central part of the cavity are cooled, and heat is transferred to the periphery of the cavity.

5. Plasma diffusion processes, as well as TAI, occur in a time comparable to the time of filling the cavity with the back ground plasma.

6. It is shown that the anomalous transport of particles and heat across the geomagnetic field in the LHC is caused to the scattering of ions by random pulsations of drift turbulence. 


\section{REFERENCES}

1. P.W. Schuck, J.W. Bonnell, P.M. Kintner. A review of lower hybrid solitary structures // IEEE Trans. Plasma Sci. 2003, v. 31, № 6, p. 1125-1177.

2. N.A. Azarenkov, D.V. Chibisov. Anomalous diffusion of plasma in the lower hybrid cavities observed in the terrestrial ionosphere // Problems of Atomic Science and Technology. Series «Plasma Physics». 2018, № 6, p. $117-120$.

3. N.A. Azarenkov, D.V. Chibisov, N.I. Kovalenko, D.I. Maslennikov. Temporal evolution of the lower hybrid cavities in the ionosphere plasma due to turbulent diffusion // Problems of Atomic Science and Technology. 2019, № 4, p. 27-30.

4. D.V. Chibisov, V.S. Mikhailenko, K.N. Stepanov. Drift wave turbulence of a radially inhomogeneous plasma // Phys. Lett. A. 1991, v. 157, p. 141-145.
5. V.S. Mikhailenko, K.N. Stepanov, D.V. Chibisov. Drift and drift-cyclotron turbulence of a radially varying axisymmetric plasma // Soviet Journal of Plasma Phyics. 1991, v. 17, № 10, p. 710-716.

6. V.S. Mikhailenko, K.N. Stepanov, D.V. Chibisov. Ion cyclotron turbulence theory of rotating plasmas // Plasma Phys. Control. Fusion. 1992, v. 34, № 1, p. 95117.

7. V.S. Mikhailenko, K.N. Stepanov, D.V. Chibisov. Drift turbulence of an azimutally symmetric radially nonuniform plasma // Plasma Phys. Rep. 1995, v. 21, № 12, p. 141-150.

\title{
АНОМАЛЬНЫЙ ПЕРЕНОС ПОПЕРЕЧНО УСКОРЕННЫХ ИОНОВ В НИЖНЕГИБРИДНЫХ ПОЛОСТЯХ
}

\author{
Н.А. Азаренков, А.Д. Чибисов, Д.В. Чибисов
}

Исследован перенос частиц и тепла для поперечно ускоренных ионов в нижнегибридных полостях в результате развития дрейфовой турбулентности. Получены уравнения переноса для условий нижнегибридных полостей. Показано, что аномальный перенос частиц и тепла поперек геомагнитного поля в нижнегибридных полостях обусловлен рассеянием ионов на случайных пульсациях дрейфовой турбулентности. Установлено, что диффузия и термодиффузия ускоренных ионов в полости происходят за время, сравнимое со временем заполнения полости окружающей плазмой.

\section{АНОМАЛЬНЕ ПЕРЕНЕСЕННЯ ПОПЕРЕЧНО ПРИСКОРЕНИХ ІОНОВ У НИЖНЬОГІБРИДНИХ ПОРОЖНИНАХ}

\section{М.О. Азарєнков, О.Д. Чібісов, Д.В. Чібісов}

Досліджено перенесення частинок і тепла для поперечно прискорених іонів $\epsilon$ нижньогібридних порожнинах у результаті розвитку дрейфової турбулентності. Отримано рівняння переносу для умов нижньогібридних порожнин. Показано, що аномальне перенесення часток і тепла поперек геомагнітного поля в нижньогібридних порожнинах обумовлене розсіюванням іонів на випадкових пульсаціях дрейфової турбулентності. Встановлено, що дифузія та термодифузія прискорених іонів у порожнині відбуваються за час, порівнянний з часом заповнення порожнини навколишньою плазмою. 